\title{
Correction to: a facile approach for fabricating CD44-targeted delivery of hyaluronic acid-functionalized PCL nanoparticles in urethane-induced lung cancer: Bcl-2, MMP-9, caspase-9, and BAX as potential markers
}

Poonam Parashar ${ }^{1} \cdot$ Chandra Bhushan Tripathi $^{1} \cdot$ Malti Arya $^{1} \cdot$ Jovita Kanoujia ${ }^{1} \cdot$ Mahendra Singh $^{1}$. Abhishek Yadav ${ }^{1}$ - Shubhini A. Saraf ${ }^{1}$

Published online: 5 May 2020

(C) Controlled Release Society 2020

Correction to: Drug Delivery and Translational Research (2019) 9:37-52

https://doi.org/10.1007/s13346-018-0575-8

In the original article the blots for BAX were inadvertently flipped in Fig. 11a. The inadvertent error in the case of BAX does not change any of the results. The corrected version is given below.

The online version of the original article can be found at https://doi.org/ $10.1007 / \mathrm{s} 13346-018-0575-8$

Shubhini A. Saraf

shubhini.saraf@gmail.com

1 Department of Pharmaceutical Sciences, Babasaheb Bhimrao, Ambedkar University (A Central University), Vidya Vihar,

Raebareli, Road, Lucknow, U.P 226025, India 
Fig. 11 a Immunoblot representing the regulation of mitochondria associated apoptosis modulating proteins isolated from lung tumor tissue of individual groups

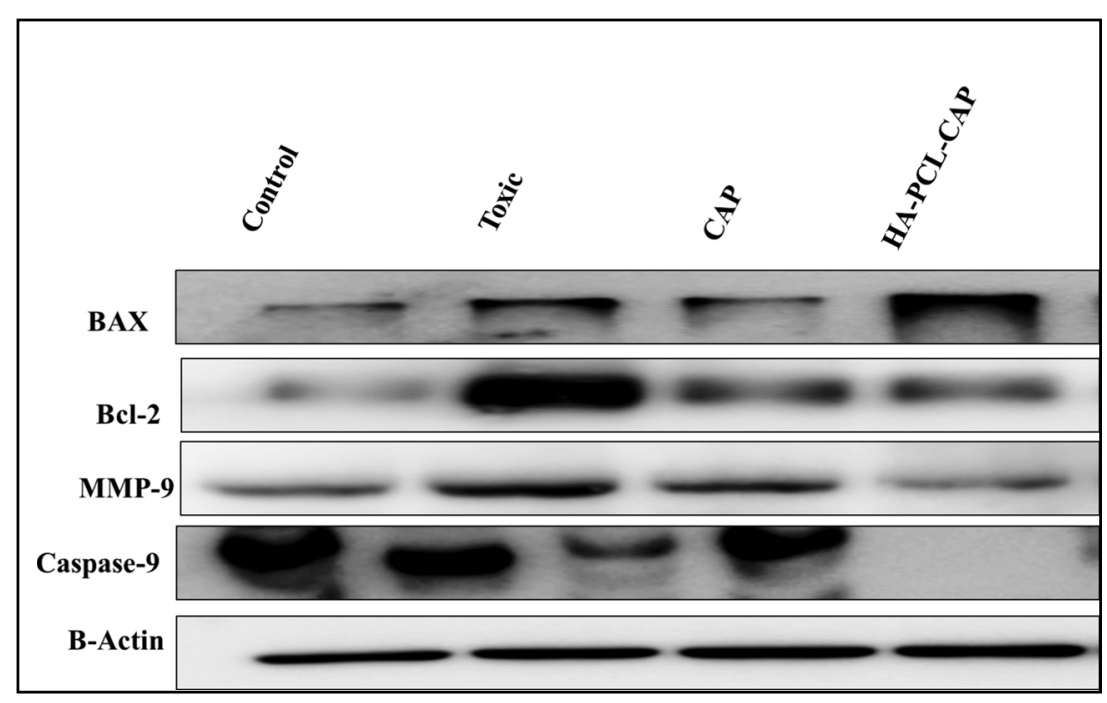

Publishe's note Springer Nature remains neutral with regard to jurisdictional claims in published maps and institutional affiliations. 